\title{
The Pyridine ring of NAD is formed by a non-enzymatic pericyclic reaction
}

\author{
Keri L. Colabroy and Tadhg P. Begley* \\ Department of Chemistry and Chemical Biology, Baker Laboratory, Cornell University, Ithaca, NY \\ 14850
}

\section{Supporting Information}

\section{Experimental}

General Information: All organic reagents were purchased from Sigma-Aldrich and used without further purification. UV-Visible detection was performed on a Hitachi-2010 spectrophotometer. NMR spectra were recorded on a Varian $400 \mathrm{MHz}$ spectrometer, and a $500 \mathrm{MHz}$ Varian spectrometer for NOE experiments.

Preparation of 3-hydroxyanthranilate-3,4-dioxygenase: Cloning, overexpression and purification of HAD was performed as previously described ${ }^{1}$. Upon purification, HAD is inactive; therefore, it was reconstituted by incubation on ice in $50 \mathrm{mM}$ phosphate, $300 \mathrm{mM} \mathrm{NaCl}, 200 \mathrm{mM}$ imidazole, $10 \mathrm{mM}$ dithiothreitol and $1-2 \mathrm{mM} \mathrm{FeSO}_{4}$ at $\mathrm{pH} 8$ for 20-60 minutes (dark red solution). The reconstituted enzyme was then rapidly gel filtered (Econo-Pac 10DG columns, Bio-Rad) into $10 \mathrm{mM}$ phosphate, $\mathrm{pH} 7.2$ for enzymatic assays. The red color was removed by gel filtration.

Assay of 3-hydroxyanthranilate-3,4-dioxygenase: Activity of purified, reconstituted HAD preparations was determined by UV-Visibile detection of the ring opened product ACMS at $360 \mathrm{~nm}\left(\varepsilon=47500 \mathrm{M}^{-1} \mathrm{~cm}^{-1}\right)^{2}$ over time after treatment of approximately 50nM HAD $(5 \mu \mathrm{l}, 0.1$ $\mathrm{mg} / \mathrm{mL})$ with $1-3 \mathrm{mM}$ 3-hydroxyanthranilate $(5 \mu 1,100-300 \mathrm{mM}$ solution in DMSO) in a final volume of $500 \mu 110 \mathrm{mM}$ phosphate, $\mathrm{pH} 7.2$.

ACMS cyclization: HAD-free ACMS was prepared first by enzymatic oxidation of 3hydroxyanthranilate, then HAD was removed from the solution of ACMS by precipitation with ice-cold chloroform $(1: 1 \mathrm{v} / \mathrm{v})$, centrifugation to remove precipitated $\mathrm{HAD}$, and subsequent ultrafiltration to remove any residual protein. The rate of cyclization of ACMS to quinolinic acid $\left(\lambda_{\max }=268 \mathrm{~nm}\right)$ was measured by monitoring the decrease in absorbance of the starting material at $360 \mathrm{~nm}$, in the presence and absence of $5 \mu \mathrm{M}(50 \mu \mathrm{l}, 60 \mu \mathrm{g})$ of purified, active HAD (see Figure $\mathrm{S} 1)$.

ACMS structure: The standard NMR spectrum of ACMS was recorded by observing the HAD catalyzed cleavage of 3-hydroxyanthranilate $(7.5 \mu \mathrm{mol})$ over time in deuterated $10 \mathrm{mM}$ phosphate pD 7.4 using a $400 \mathrm{mHz}$ Varian NMR. The NOE experiment was performed on a 500MHz Varian NMR. Each of the three protons of ACMS was specifically irradiated, and the NOE observed in one dimension. The only NOE observed was between H4 and H6 of ACMS.

N,N-dimethylcarbamoylpyridine $(\mathbf{8}): \mathbf{8}$ was prepared by reaction of anhydrous pyridine (180ul, $2.2 \mathrm{mmol})$ with dimethylcarbamylchloride ${ }^{3}(200 \mathrm{ul}, 2.2 \mathrm{mmol})$ with stirring under argon. When a 
yellow semisolid formed, 400ul anhydrous acetonitrile and additional dimethylcarbamylchloride $(100 \mathrm{ul}, 1.1 \mathrm{mmol})$ were added and stirring continued for several hours at room temperature. Water was added to decompose unreacted dimethylcarbamylchloride, and the reaction mixture was dried under vacuum. The product $\mathbf{8}$ was isolated as a yellow semisolid that was stable when stored at $-20^{\circ} \mathrm{C}$. NMR (400MHz) $\mathrm{D}_{2} \mathrm{O}: 2.76 \mathrm{ppm}\left(\mathrm{NCH}_{3 \mathrm{a}}, \mathrm{s}\right), 3.05 \mathrm{ppm}\left(\mathrm{NCH}_{3 \mathrm{~b}}, \mathrm{~s}\right) 8.0 \mathrm{ppm}(1 \mathrm{H}, \mathrm{tr}$, $J=7.0 \mathrm{~Hz}), 8.6 \mathrm{ppm}(1 \mathrm{H}, \mathrm{tr}, J=7.9 \mathrm{~Hz}), 8.9 \mathrm{ppm}(1 \mathrm{H}, \mathrm{d}, J=6.8 \mathrm{~Hz})$.

Ring opening of 8 to 14,15 , and 16: $3 \mathrm{M}$ sodium methoxide was prepared by addition of sodium metal to methanol, freshly distilled from heat activated molecular sieves. 3M sodium deuteroxide was prepared by addition of sodium hydroxide to $\mathrm{D}_{2} \mathrm{O} .87 \mu \mathrm{mol}(13 \mathrm{mg})$ of 8 was dissolved in either $\mathrm{CD}_{3} \mathrm{OD}$ or $\mathrm{D}_{2} \mathrm{O}$ in the NMR tube, followed by addition of $20 \mu 13 \mathrm{M} \mathrm{NaOMe}(0.7$ equiv) or $3 \mathrm{M} \mathrm{NaOD}$ ( 0.7 equiv). Upon addition of either nucleophile, the reaction mixture instantly turned a very bright yellow. The NMR spectrum of the reaction mixture was taken immediately following nucleophile addition and followed over time. By NMR, the reaction was complete by the earliest time point. After 16 hours, the methoxide opened product 16 was dried under vacuum. The residual solid was dissolved in $\mathrm{D}_{2} \mathrm{O}$ and the spectrum taken for direct comparision to 14 and 15. After 16 hours, the mixture of $\mathbf{1 4}$ and $\mathbf{1 5}$ was also dried under vacuum, and the solid residue dissolved in $\mathrm{CD}_{3} \mathrm{OD}$ for additional direct comparison. The NMR spectra of the ring opened products are described in the Tables and Figures below. 


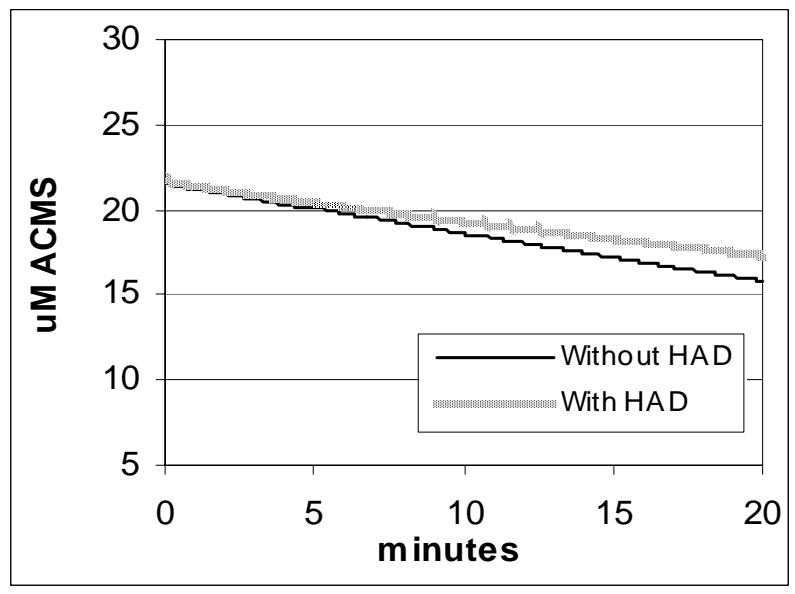

Figure 1. Cyclization of ACMS (2) to quinolinate (3) in the presence and absence of HAD. The cyclization was monitored by measuring the decrease in the absorbance of the intensely yellow ACMS chromophore at $360 \mathrm{~nm}$. The "enzymatic" and non-enzymatic cyclization rates were $0.21 \mu \mathrm{M} / \mathrm{min}$ and $0.28 \mu \mathrm{M} / \mathrm{min}$ respectively.

Table S1. Chemical shifts and coupling constants for 14 in $\mathrm{D}_{2} \mathrm{O}$.

\begin{tabular}{|l|l|l|l|}
\hline Proton & Chemical Shift $(\mathrm{ppm})$ in $\mathrm{D}_{2} \mathrm{O}$ & Coupling Constant 1 (Hz) & Coupling Constant 2 (Hz) \\
\hline $\mathrm{H} 1$ & 7.31 & $13.7-13.8$ & ---- \\
\hline $\mathrm{H} 2$ & 5.93 & $13.7-13.8$ & $11.7-11.8$ \\
\hline $\mathrm{H} 3$ & 7.29 & $11.7-11.8$ & $14.8-15.4$ \\
\hline $\mathrm{H} 4$ & 5.87 & $14.8-15.4$ & $8.6-8.7$ \\
\hline $\mathrm{H} 5$ & 9.04 & $8.6-8.7$ & ---- \\
\hline $\mathrm{NCH}_{3 \mathrm{a}}$ & 2.50 & ---- & ---- \\
\hline $\mathrm{NCH}_{3 \mathrm{~b}}$ & 2.60 & ---- & ---- \\
\hline
\end{tabular}

Table S2. Chemical shifts and coupling constants for $\mathbf{1 5}$ in $\mathrm{D}_{2} \mathrm{O}$

\begin{tabular}{|l|l|l|l|}
\hline Proton & Chemical Shift $(\mathrm{ppm})$ in $\mathrm{D}_{2} \mathrm{O}$ & Coupling Constant 1 (Hz) & Coupling Constant 2 $(\mathrm{Hz})$ \\
\hline $\mathrm{H} 1$ & 7.82 & $10.74-10.95$ & ---- \\
\hline $\mathrm{H} 2$ & 6.17 & 10.8 & $13.8-14.0$ \\
\hline $\mathrm{H} 3$ & 7.38 & $11.8-12.0$ & $13.8-14.0$ \\
\hline $\mathrm{H} 4$ & 6.04 & $11.9-12.0$ & $13.3-13.4$ \\
\hline $\mathrm{H} 5$ & 7.54 & $13.3-13.4$ & ---- \\
\hline $\mathrm{NCH}_{3 \mathrm{a}}$ & 3.12 & ---- & ---- \\
\hline $\mathrm{NCH}_{3 \mathrm{~b}}$ & 3.28 & ---- & ---- \\
\hline
\end{tabular}

Table S3. Chemical Shifts and coupling constants for $\mathbf{1 6}$ in $\mathrm{D}_{2} \mathrm{O}$.

\begin{tabular}{|l|l|l|l|}
\hline Proton & Chemical Shift $(\mathrm{ppm})$ in $\mathrm{D}_{2} \mathrm{O}$ & Coupling Constant 1 (Hz) & Coupling Constant 2 (Hz) \\
\hline $\mathrm{H} 1$ & 7.86 & 11.05 & ---- \\
\hline $\mathrm{H} 2$ & 6.20 & 11.05 & 13.9 \\
\hline $\mathrm{H} 3$ & 7.40 & 13.9 & $11.8-11.9$ \\
\hline $\mathrm{H} 4$ & 6.06 & $11.8-11.9$ & 13.4 \\
\hline $\mathrm{H} 5$ & 7.53 & 13.4 & ---- \\
\hline $\mathrm{OCH}_{3}$ & 3.04 & --- & ---- \\
\hline $\mathrm{NCH}_{3 \mathrm{~b}}$ & 3.14 & ---- & ---- \\
\hline $\mathrm{NCH}_{3 \mathrm{a}}$ & 3.29 & ---- & ---- \\
\hline
\end{tabular}




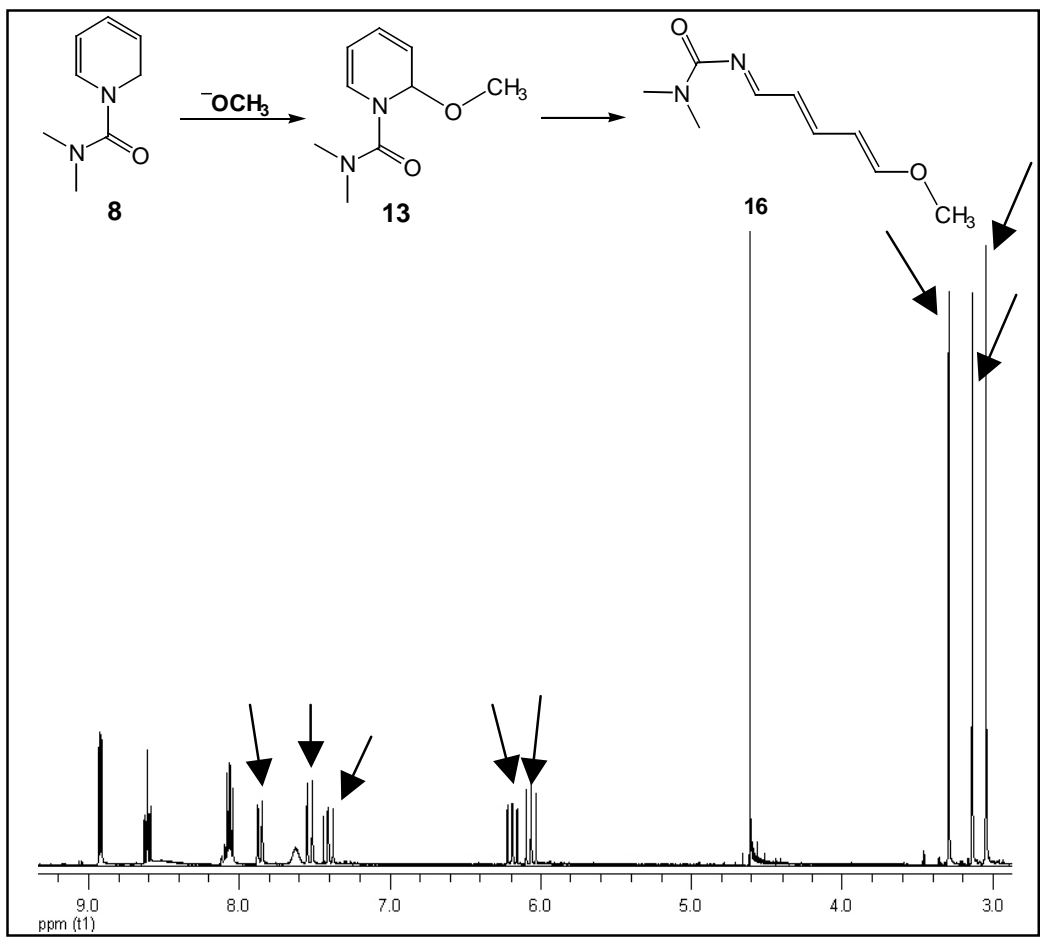

Figure S2. Reaction of sodium methoxide with 8. Spectrum shows the aromatic protons of unreacted $\mathbf{8}$, and the protons of $\mathbf{1 6}$ (indicated by arrows). 


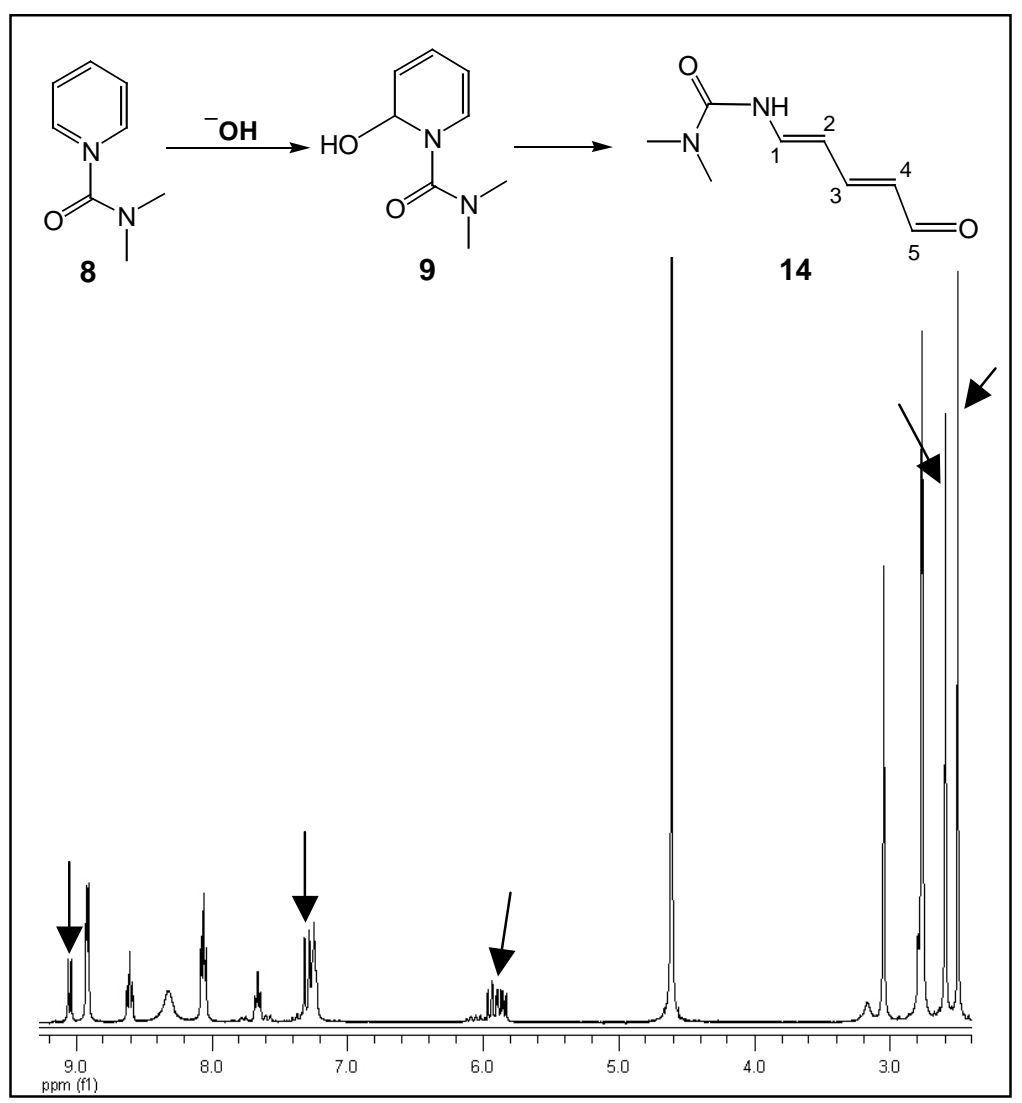

Figure S3. Immediately following reaction of sodium hydroxide with 8 in $\mathrm{D}_{2} \mathrm{O}$. Spectrum shows the dominant tautomer is $\mathbf{1 4}$ (indicated by arrows), with unreacted $\mathbf{8}$ present as well. 


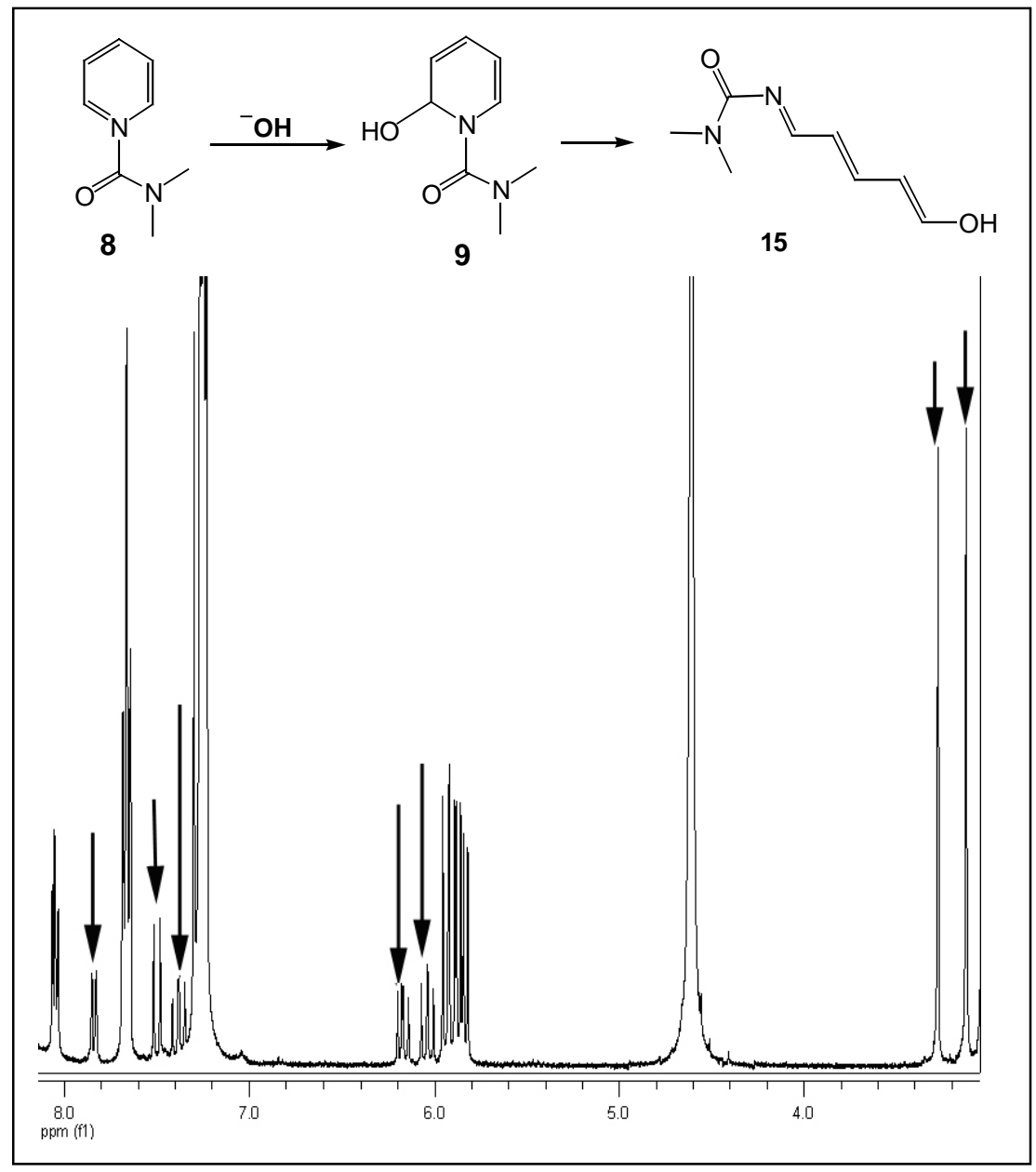

Figure S4. Reaction of sodium hydroxide with 8 in $\mathrm{D}_{2} \mathrm{O}$ after approximately 16 hours. Product $\mathbf{1 4}$ has equilibrated with its tautomer 15, the peaks of which are indicated by the arrows in the spectrum above. The other peaks belong to unreacted $\mathbf{8}$, and tautomer $\mathbf{1 4}$.

(1) Kurnasov, O., Goral, V., Colabroy, K., Gerdes, S., Anantha, S., Osterman, A. and Begley, T. Chemistry and Biology 2003, 10, 1195-1204.

(2) Koontz, W.; Shiman, R. The Journal of Biological Chemistry 1976, 251, 368-377.

(3) Johnson, S. L. a. R., K.A. The Journal of Physical Chemistry 1964, 68, 3149-3154. 